\title{
Appendix Neuroendocrine Tumor by AJCC v8 Stage
}

National Cancer Institute

\section{Source}

National Cancer Institute. Appendix Neuroendocrine Tumor by A/CC v8 Stage. NCI

Thesaurus. Code C135156.

A term that refers to the staging of an appendiceal neuroendocrine tumor, following the rules of the TNM AJCC v8 classification system. This staging system applies to appendiceal NETs (carcinoid tumors) (NET G1 and G2, and rare well-differentiated G3). High-grade neuroendocrine carcinomas (NEC), goblet cell carcinoids, mixed adenocarcinomas, and adenocarcinomas of the appendix are not staged using this staging system. (from AJCC 8th Ed.) 